\title{
小鼠精子顶体反应中腺苷酸环化酶和环核 苷酸磷酸二酯酶调节作用的研究 ${ }^{*}$
}

\author{
段崇文 胡国俊 陈大元 \\ (中国科学院动物研究所计划生育生殖生物学国家重点实验室, 北京 100080)
}

\section{关键词顶体反应 腺苷酸化酶 环核苷酸磷酸二酯酶 调节作用}

自从 Austin 和 Chang 提出获能以来, 已有很多学者对哺乳动物精子获能的形态及生化变 化进行了研究, 并逐渐进人到分子机理的研究. Cascien 等 (1976) 报道了牛精子获能之初的腺 甘酸变化, Fraser(1979) 报道了咖啡因加速小鼠精子体外穿卵过程, Chan 等 (1981) 报道了精 子获能及顶体反应过程中有环核苷酸参与, 紧接着 Fraser(1981) 发现 dbcAMP 能缩短获能时 间 ${ }^{[1]}$ 及与 cAMP 相关的 $\mathrm{Ca}^{2+}$ 浓度变化 ${ }^{[2]}$, 指出获能必须有 $\mathrm{Ca}^{2+}$ 参加, 其后 Monks(1987) 又报 道小鼠精子中具有腺草酸环化酶和环核苷酸磷酸二酯酶活性 ${ }^{[3]}$, 由此可见, 精子获能过程中 存在着 $\mathrm{Ca}^{2+}$, cAMP 及两种酶的调节系统. 为探讨上述各因素之间的关系, 我们采用几种影 响和调节上述因素的外源因子, 观察其对小鼠精子体外获能的影响, 并以精子获能为指 标, 探讨上述因素之间的关系及其对精子获能及精子顶体反应的影响, 以便进一步讨论精子 获能的分子机制.

\section{1 材料与方法}

\section{1 精子体外获能}

昆明系雄性小鼠, 12 周龄, 控光 $(\mathrm{D}: \mathrm{N}=14: 10)$ 饲养. 动物颈椎脱臼处死, 迅速取下附睪 尾及输精管, 放人盛有 $3 \mathrm{~mL}$ 培养液的 $30 \mathrm{~mm}$ 塑料培养血中, 并稍剪碎. 然后培养血置 37 ${ }^{\circ} \mathrm{C}, 5 \% \mathrm{CO}_{2}$ 培养箱中孵育 $5 \mathrm{~min}$, 使活精子游出之后, 取上层培养液, $2000 \mathrm{r} / \mathrm{min}$ 离心使精子沉 降, 沉淀加人 $3 \mathrm{~mL}$ 新鲜培养液并转人 $30 \mathrm{~mm}$ 培养血, 再次放人上述 $37^{\circ} \mathrm{C}, 5 \% \mathrm{CO}_{2}$ 培养箱中 培养 $1 \mathrm{~h}$, 相差显微镜观察, 以确定精子获能效果.

\section{2 培养液}

实验所用培养液为购自 Sigma 的 Tyrode's 液 (T2145). 溶液以 $\mathrm{NaHCO}_{3}$ 调 $\mathrm{pH}$ 为 7.4, 再 加人 BSA 至终浓度为 $4 \mathrm{mg} / \mathrm{mL} .0 .22 \mu \mathrm{m}$ 微孔滤膜过滤除菌. 实验设计下列 7 组培养系统:

(1) 对照组: 精子正常培养液组, (2)EDTA 组:精子正常培养液加 $2 \mathrm{mmol} / \mathrm{L}$ EDTA 组, (3) Quer 组: 精子正常培养液加 $50 \mu \mathrm{mol} / \mathrm{L}$ 料皮素 (Quercetin) 组, (4)Fosk 组: 精子正常培养液 加 $5 \mu \mathrm{mol} / \mathrm{L}$ Foskolin 组, (5)EDTA + Fosk 组: 精子正常培养液加 $2 \mathrm{mmol} / \mathrm{L}$ EDTA 及 $5 \mu \mathrm{mol} / \mathrm{L}$

1994-10-24 收稿, 1995-02-26 收修改稿

*中国科学院 “八五”攻关重点资助项目 
Foskolin 组, (6) EDTA+cAMP 组: 精子正常培养液加 $2 \mathrm{mmol} / \mathrm{L}$ EDTA 及 $15 \mu \mathrm{mol} / \mathrm{L}$ dbcAMP 组, (7) Endo 组: 精子正常培养液加 $0.1 \mu \mathrm{mol} / \mathrm{L} \beta$ - 内啡肽 ( $\beta$-Endophin) 组. 7 组实 验均同时重复进行 3 次.

\section{3 材料固定及电镜样品制备}

各组精子体外获能 $1 \mathrm{~h}$ 后, 经 $2000 \mathrm{r} / \mathrm{min}$ 离心收集沉淀, $3 \%$ 戊二醛, $0.5 \%$ 多聚甲醛, 0.1 $\mathrm{mol} / \mathrm{L} \mathrm{CaCo}$ 混合固定液固定 $2 \mathrm{~h}, 4^{\circ} \mathrm{C}$, 然后用 $0.1 \mathrm{~mol} / \mathrm{L} \mathrm{CaCo}$ 缓冲液漂洗过夜. 次日材料 经 $1 \%$ 锇酸, $0.1 \mathrm{~mol} / \mathrm{L} \mathrm{CaCo}$ 固定液后固定 $1 \mathrm{~h}$ 后, 系列酒精脱水, $\mathrm{Spurr}$ 包埋. 薄切片经 铀、铅染色后 JEM-2000EX 电镜观察.

\section{2 结果与讨论}

薄切片在电镜上观察, 以顶体膨胀为精子获能、顶体反应初始的指标, 统计每一组材料的 任意 300 个精子中, 经过了顶体膨胀时期的精子个数所占 300 个精子中的比例, 以此衡量不同 因子对精子顶体反应的影响, 从而推测 $\mathrm{Ca}^{2+}, \mathrm{cAMP}$ 与腺苷酸环化酶及环核苷酸磷酸二酯酶 之间的关系及对精子获能的影响.

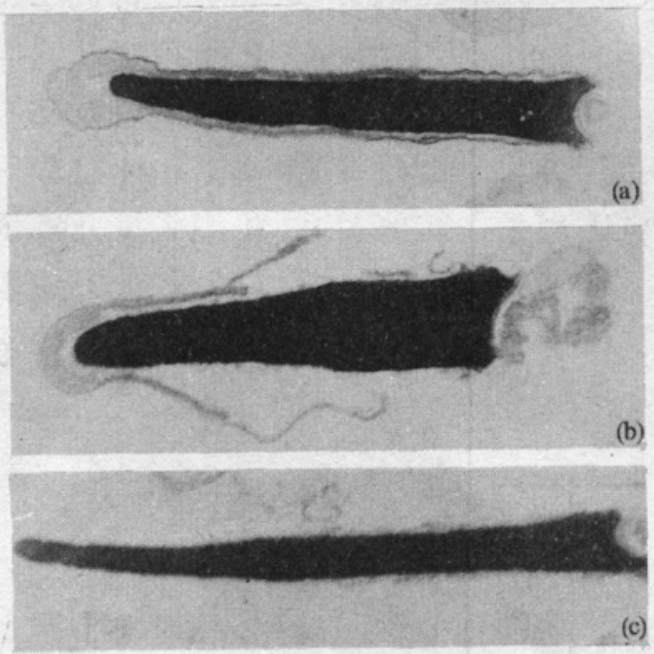

图 1 电镜下判断不同时期精子的形态标准 (a) 顶体完整为未获能精子, (b) 顶体膨胀为获能和 顶体反应初始精子, (c) 顶体脱落为顶体反应完毕 - 精子
对各种精子鉴定的形态标准由图 1 示, 未获 能精子 (图 1(a))、顶体膨胀精子 (图 1(b))、顶体脱 落精子(图 1(c)).

对照组: 3 次实验经过了顶体膨胀时期的精 子数分别为 $51,63,61$ 个, 各占总数 300 个精子 的 $17 \%, 21 \%, 20.3 \%$, 并且绝大多数为顶体 膨胀, 偶见有顶体脱落者.

EDTA 组: 加人 $2 \mathrm{mmol} / \mathrm{L}$ EDTA, 使得正 常培养中 $\mathrm{Ca}^{2+}$ 被结合, 失去游离 $\mathrm{Ca}^{2+}$, 此时电镜 观察发现, 3 组实验各 300 个精子中分别有 4, 5, 5 个精子顶体膨胀, 各占总数的 $1.3 \%, 1.7 \%, 1.7 \%$. 精子获得能所需的最大和最小 $\mathrm{Ca}^{2+}$ 浓度, Fraser (1987) 已有证明 ${ }^{[4]}$ ，本实验再次证明没有 $\mathrm{Ca}^{2+}$ 精 子不能获能.

Quer 组: 加人櫯皮素, 是 $\mathrm{Ca}^{2+}-\mathrm{ATPase}$ 的专 一性抑制剂, 抑制 $\mathrm{Ca}^{2+}$-ATPase 对 $\mathrm{Ca}^{2+}$ 的主动运输, $30 \sim 100 \mu \mathrm{mol} / \mathrm{L}$ 即可抑制肌浆网摄取 $\mathrm{Ca}^{2+}$. 这一组中, 3 次实验各 300 个精子中分别有 $65,85,81$ 个精子经过了顶体膨胀期, 各占 $21.7 \%, 28.3 \%, 27 \%$, 略高于对照组, 但其中已见有顶体帽脱落者, 说明料皮素对精子获能有 促进作用, Bradley 和 Forrester(1982) 曾报道羊精子表面 $\mathrm{Ca}^{2+}$-ATPase 引起 $\mathrm{Ca}^{2+}$ 外流 ${ }^{[5}$, Fraser (1984) 又报道小鼠精子表面有 $\mathrm{Ca}^{2+}-\mathrm{ATP}$ ase 将精子内 $\mathrm{Ca}^{2+}$ 泵出 ${ }^{[6}$. 本实验证明, 小鼠精子表 面的 $\mathrm{Ca}^{2+}$-ATPase 能主动将 $\mathrm{Ca}^{2+}$ 转运到精子外, 抑制 $\mathrm{Ca}^{2+}-\mathrm{ATP}$ ase 对 $\mathrm{Ca}^{2+}$ 的外运, 能提高精 子内 $\mathrm{Ca}^{2+}$ 浓度, 有利于精子获能.

Fosk 组: Foskolin 是腺苷酸环化酶的促进剂, 在此培养液中, 3 次实验各 300 个精子分别 有 $82,98,102$ 个精子经历了顶体膨胀, 其中各有 $11,10,15$ 个已经顶体脱落, 获能精子数明 
显高于对照组, 本实验证明了腺苷酸环化酶的促进剂能促进精子获能, 缩短精子获能时间, 同 时说明腺苷酸环化酶在精子获能和顶体反应过程中起正调节作用.

EDTA + Fosk 组：同时加人 EDTA 和 Foskolin, 统计精子获能情况表明, 3 次实验分别仅 有 7, 7, 5 精子获能, 占统计总数 300 个精子的 $2.3 \%, 2.3 \%, 1.7 \%$, 并且获能精子中没有顶体 帽脱落者, 该结果与第二组实验相似. 实验表明, Foskolin 对腺葉酸环化酶的促进作用, 必须 有 $\mathrm{Ca}^{2+}$ 存在, 如果没有 $\mathrm{Ca}^{2+}$, Foskolin 不能刺激腺苷酸环化酶合成 cAMP, 同时我们推测小鼠 精子中的腺苷酸环化酶是 $\mathrm{Ca}^{2+}$ 依赖型的, 没有 $\mathrm{Ca}^{2+}$ 则酶没有活性.

EDTA + cAMP 组: 同时加人 dbcAMP 和 EDTA, 观察统计表明, 3 次实验各 300 个精子 中已分别有 48, 66, 69 个精子经过了顶体膨胀期, 其中 12, 19, 17 个已经顶体脱落, 精子获能 率分别为 $16 \%, 22 \%, 23 \%$ ，从获能精子比例看与对照组相似, 但从顶体反应率看, 比对照明 显增加, 说明 cAMP 能直接引起精子获能和顶体反应. 从本实验我们认为精子获能实际上是 精子内部cAMP 聚集的过程, 当cAMP 达到一定浓度时, 诱发精子顶体反应. 外源加人 cAMP, 此时虽然无 $\mathrm{Ca}^{2+}$, 二种酶均无活性, 但由于 cAMP 是膜通透性的, 培养液中的 cAMP 能进人精子内, 使得精子内已有了获能的产物, 精子同样能发生顶体反应.

Endo 组: 加人 $\beta$-Endo, 观察统计表明, 3 次实验各 300 个精子中已分别有 127, 153，147 个 精子经过顶体膨胀期, 并且有 58,76,75 个已经顶体反应, 顶体脱落. 获能精子分别占统计总 数的 $42.5 \%, 51 \%, 49 \%$, 顶体反应占全部获能精子的 $45.7 \%, 49.7 \%, 51 \%$, 实验表明 $\beta$-Endo 能有效地刺激精子获能,精子的反应,胜过上述几种因子. $\beta$-Endo 的作用是专一性抑制 CaM 对 环核苷酸磷酸二酯酶的激活作用, 从而证明,精子内环核苷酸磷酸二酯酸是受 CaM 激活. 由 于 $\beta$-Endo 抑制作用, 使得环核苷酸磷酸二酯酶失活, 从而导致 cAMP 的降解被抑制, cAMP 聚 集加快, 诱发了精子顶体反应.

7 组实验结果如图 2.

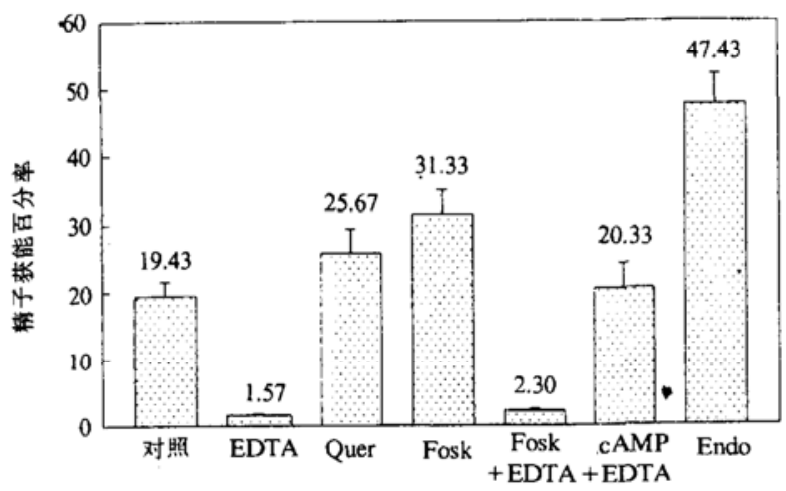

图 2 各组实验精子获能的百分率

现有的研究表明,细胞内腺苷酸环化酶和环核甘酸磷酸二酯酶都由 CaM 激活, 结合我们 的实验, 我们认为, 精子获能过程时, 首先是精子内 $\mathrm{Ca}^{2+}$ 浓度上升, 激活 $\mathrm{CaM}$, 由 $\mathrm{CaM}$ 激活腺 苷酸环化酶和环核苷酸磷酸二酯酶。此二酶调节着 cAMP 浓度缓慢上升, 其详细机制有待进 一步研究其酶动力等. 当精子内 cAMP 上升到一临界点便诱发精子顶体反应, 而获能过程则 是 cAMP 聚集的过程. 提高腺苷酸环化酶活性,抑制环核苷酸磷酸二酯酶活性, 增加 cAMP, 都能缩短精子获能时间, 促进精了顶体反应. 
全部结果简示于图 3.

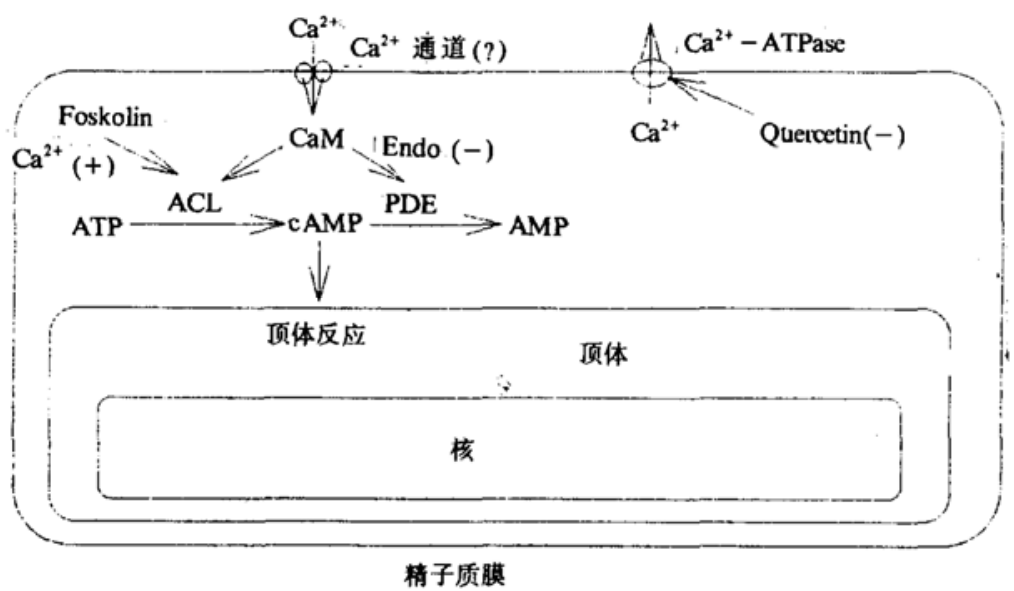

图 3 几种因子在精子获能中的作用

$\mathrm{CaM}$ 为钙调蛋白, $\mathrm{ACL}$ 为腺苦酸环化酶, PDE为环核苷酸磷酸二酯酶

致谢 本室电镜室齐跃敏同志在本实验电镜观察中给予帮助，在此表示感谢．

\section{参考文献}

1 Fraser L R. Dibutyl cyclic AMP decrease capacitation time in vitro in mouse spermatozoa. J Reprod Fertil, 1981, 62: $63 \sim 72$

2 Fraser L R. $\mathrm{Ca}^{2+}$ is required for mouse sperm capacitation and fertilization in vitro. J Androl, 1982, 3:412 418

3 Monks N J, fraser L R. Phosphodiesterase activity of mouse sperm incubated under conditions that modulate fertilization potential in vitro. Gamete Res, 1987, 18: 85 96

4 Fraser L Y. Minimum and maximum extracellular $\mathrm{Ca}^{2+}$ requirement during sperm capacitation and fertilization in vitro. J Reprod Fertil, 1987, 81:77 89

5 Bradley M P, Forrester I T. Human and ram seminal plasma both contain a calcium-dependent regulator protein calsemin. J Androl, 1982, 3:289 296

6 Fraser L Y, Ahuja K K. Metabolic and surface events in fertilization. Gamete Res, 1988, 20: 491 519 